\title{
Temperate macroalgae impacts tropical fish recruitment at forefronts of range expansion
}

\author{
H. J. Beck ${ }^{1}$ - D. A. Feary ${ }^{1}$ Y. Nakamura ${ }^{2}$ D. J. Booth ${ }^{1}$
}

Received: 15 October 2015/Accepted: 25 January 2017

(C) Springer-Verlag Berlin Heidelberg 2017

\begin{abstract}
Warming waters and changing ocean currents are increasing the supply of tropical fish larvae to temperature regions where they are exposed to novel habitats, namely temperate macroalgae and barren reefs. Here, we use underwater surveys on the temperate reefs of southeastern (SE) Australia and western Japan $\left(\sim 33.5^{\circ} \mathrm{N}\right.$ and $\mathrm{S}$, respectively) to investigate how temperate macroalgal and non-macroalgal habitats influence recruitment success of a range of tropical fishes. We show that temperate macroalgae strongly affected recruitment of many tropical fish species in both regions and across three recruitment seasons in SE Australia. Densities and richness of recruiting tropical fishes, primarily planktivores and herbivores, were over seven times greater in non-macroalgal than macroalgal reef habitat. Species and trophic diversity $(K$ dominance) were also greater in non-macroalgal habitat. Temperate macroalgal cover was a stronger predictor of tropical fish assemblages than temperate fish assemblages, reef rugosities or wave exposure. Tropical fish richness, diversity and density were greater on barren reef than on reef dominated by turfing algae. One common species, the neon damselfish (Pomacentrus coelestis), chose non-
\end{abstract}

Communicated by Biology Editor Dr. Andrew Hoey

Electronic supplementary material The online version of this article (doi:10.1007/s00338-017-1553-1) contains supplementary material, which is available to authorized users.

\section{H. J. Beck}

hbeck84@gmail.com

1 School of Life Sciences, University of Technology Sydney, Broadway, P.O. Box 123, Ultimo, NSW 2007, Australia

2 Graduate School of Kuroshio Science, Kochi University, 200 Monobe, Nankoku, Kochi 783-8502, Japan macroalgal habitat over temperate macroalgae for settlement in an aquarium experiment. This study highlights that temperate macroalgae may partly account for spatial variation in recruitment success of many tropical fishes into higher latitudes. Hence, habitat composition of temperate reefs may need to be considered to accurately predict the geographic responses of many tropical fishes to climate change.

Keywords Climate change - Kelp forest - Novel habitat . Poleward range shift . Temperate rocky reef - Reef fishes

\section{Introduction}

Ocean warming is leading to rapid and widespread poleward shifts in the geographic distribution of many marine species (Thomas et al. 2004; Harley et al. 2006). This climate-driven redistribution of marine organisms is altering the composition and food web structure of coastal ecosystems. Such climate-driven ecological changes often negatively affect human societies that depend on coastal ecosystems for resources and economic stability (Cheung et al. 2009; Pereira et al. 2010). To manage ecological impacts of climate change and their associated socioeconomic consequences (Burrows et al. 2014), accurate predictions of the timing and location of species redistribution are required (Frusher et al. 2014). Nevertheless, factors that regulate the colonisation of new ranges are largely unresolved (Hellmann et al. 2012; HilleRisLambers et al. 2013; Urban et al. 2013). Certainly, supply of larval propagules into new ranges (Gaylord and Gaines 2000; Keith et al. 2011) and climate at higher latitudes (Pinsky et al. 2013) may primarily determine how species respond to shifting isotherms. However, for reef-associated organisms, 
availability of suitable reef habitats may ultimately determine whether they colonise higher latitudes (e.g. Hill et al. 2001; Warren et al. 2001; Honnay et al. 2002; Travis 2003; Cheung et al. 2010; Mair et al. 2014).

Changes in the extent and strength of poleward-flowing currents may increase the thermal suitability of many temperate regions for tropical fishes (including Australia, Japan, Korea, western Africa, Brazil and USA; Wu et al. 2012; Beck 2014). Temperate rocky reefs present a myriad of foreign biophysical conditions that may influence the poleward redistribution of tropical reef fishes. These novel reef environments may determine where these fish recruit (i.e. from settlement to reef habitat to survival to inclusion in existing assemblages), and thus ultimately colonise, by determining access to suitable resources. Interactions with native predators and competitors may also inhibit tropical fish recruitment. However, the role of temperate reef habitats in influencing tropical fish recruitment currently remains poorly understood (Beck 2014). To date, it has been shown that wave-protected temperate reefs offer a safe haven for many tropical fish recruits, at least at spatial scales of hundreds of metres (Beck et al. 2016a). Lower densities of temperate predators are also known to improve chances of overwinter success (Beck et al. 2016b). Warmer winter water temperatures assist survival of tropical fishes by facilitating better physiological performance, hence improving access to resources, including food (Beck et al. 2016b).

A key remaining question is how temperate macroalgae impact tropical reef fish recruitment. Spatial heterogeneity in the physical structure, resources and associated temperate reef fish communities between temperate macroalgal forests (canopy, subcanopy and basal layers) and patches of algal turf and/or barren reef (covered by ephemeral or encrusting algae or bare reef; Curley et al. 2002) may lead to patchiness in tropical reef fish recruitment (Shulman 1984, 1985; Beukers and Jones 1998; Almany 2004). On coral reefs, many tropical reef fishes avoid algae-dominated areas. Such avoidance has previously been attributed to physical movement of algal habitats in association with wave action, low availability of suitable fine-scale microshelter, higher predation risk in dense macroalgal areas and/or undesirable chemical cues from seaweed-dominated reefs (Hoey and Bellwood 2011; Lecchini et al. 2013; Dixson et al. 2014). Conversely, a small proportion of tropical fish recruits have been found to positively associate with the structural complexity and potential food sources provided by macroalgal patches in tropical regions (Lecchini et al. 2007; Wilson et al. 2010; Evans et al. 2014; Yamada et al. 2012; Hoey et al. 2013). Tropical fishes may also respond to macroalgae differently on temperate than tropical reefs. For instance, the shape and movement characteristics of common temperate brown algae, such as Ecklonia spp. and Phyllospora spp., differ to that of tropical macroalgal communities, which are often dominated by Sargassum spp. Temperate macroalgae also support different suites of biological communities (including potential predators and competitors) than tropical macroalgae (Kuiter 1993), which may influence tropical fish recruitment. Understanding at the seascape level how temperate macroalgae influence recruitment of tropical fishes may allow managers to more accurately predict impacts of these invading species. These impacts so far include overgrazing of algae and increased competition for resources and predation pressure on temperate reefs (Masuda et al. 2000; Feary et al. 2014; Vergés et al. 2014).

Here, temperate coastal reefs of south-eastern (SE) Australia and western (W) Japan were used to investigate how temperate macroalgal communities structure the density, richness and diversity of colonising tropical reef fishes. Many tropical fishes are supplied to SE Australia and W Japan by poleward-flowing boundary currents: the East Australian Current in Australia and the Kuroshio Current in Japan (Fig. 1). In these regions, tropical fishes commonly recruit to coastal temperate reefs throughout summer. Although cool waters currently constrain many of these warm-adapted fishes from surviving through winter, coastal waters in W Japan and SE Australia are warming at more than twice the global average (Wu et al. 2012). Such rapid warming is expected to facilitate the ongoing colonisation of an increasing range of tropical fish species (Figueira et al. 2009; Figueira and Booth 2010).

We examined the influence of temperate macroalgal cover on recruitment of tropical reef fishes by comparing the density, richness and diversity of new recruit and juvenile tropical fishes (hereafter termed 'vagrants') between macroalgal habitat (genera Ecklonia, Phyllospora and Sargassum) and non-macroalgal habitats. Nonmacroalgal habitats were defined as consisting of low-lying turfing algae (Class Rhodophyta and Phylum Phaeophyceae) or barren rocky reef (rock covered in encrusting and ephemeral Rhodophyta and Phaeophyceae, or bare rock with no algae). To examine factors that possibly contributed to differences in recruitment of tropical fishes among non-macroalgal and macroalgal reef patches, reef structure (topographical complexity), wave exposure, temperate reef fish community (including likely competitors and predators) and benthic composition were also quantified. We conducted aquarium experiments using a common tropical damselfish (Pomacentrus coelestis) to test whether the observed habitat associations of vagrants resulted from preference during larval settlement (shift from pelagic to benthic life stage), rather than immigration and/or differential mortality. 


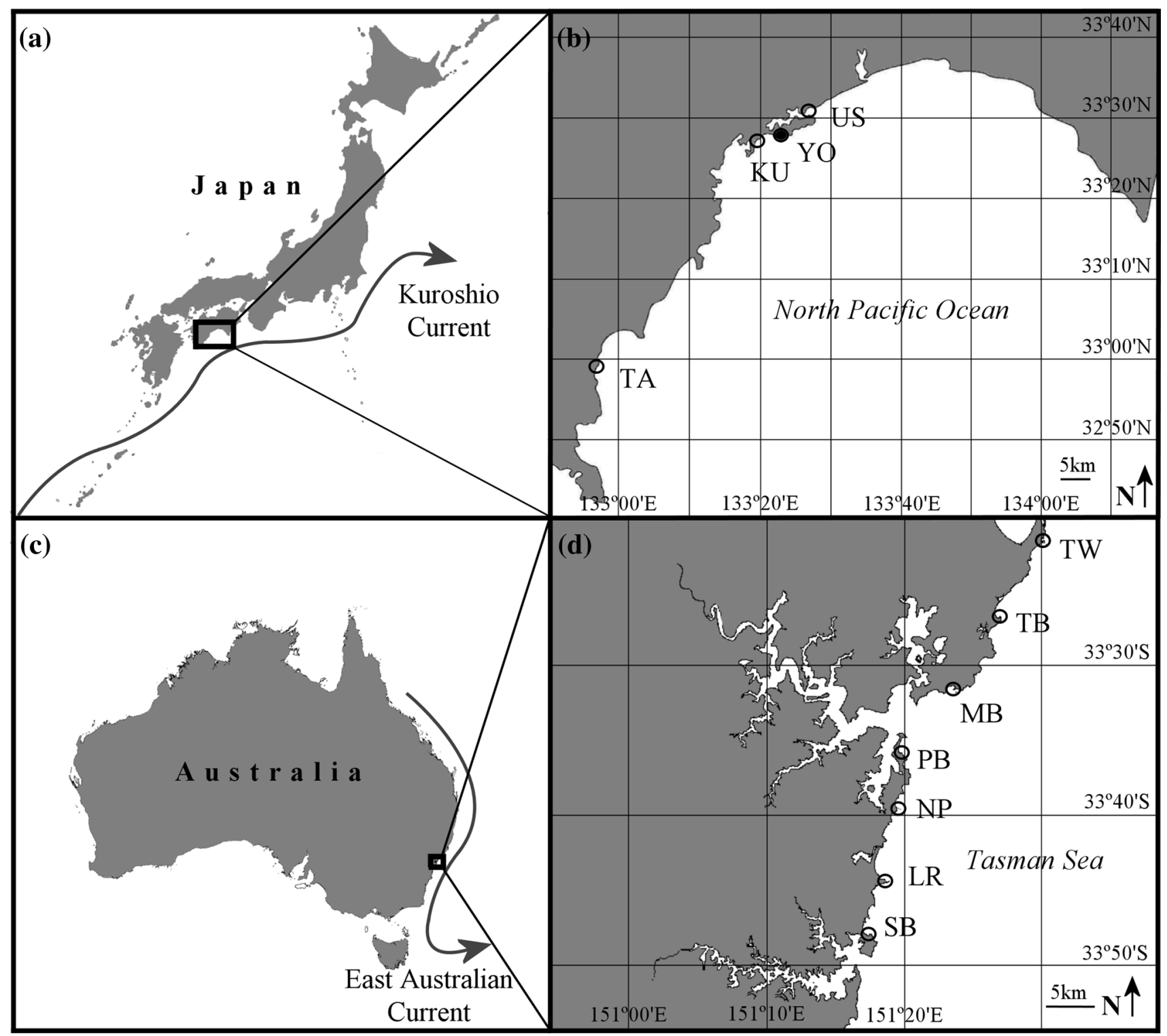

Fig. 1 Survey sites (open circles) within western Japan (a, b) and south-eastern Australia (c, d). $S B$ Shelly Beach; $L R$ Long Reef; Newport; $P B$ Palm Beach; $M B$ Maitland Bay; $T B$ Terrigal Beach; $T W$

\section{Materials and methods}

\section{Tropical fish recruitment to macroalgal and non- macroalgal temperate reefs}

Underwater visual surveys of new recruit and juvenile vagrant fishes were conducted in summer and early autumn when the fish recruit to coastal temperate reefs of SE Australia (January-May 2011, 2012 and 2014) and W Japan (July 2013; Kuiter 1993; Booth et al. 2007; Nakamura et al. 2013). Australian and Japanese study sites were located at $\sim 33.5^{\circ} \mathrm{S}$ and $\mathrm{N}$, respectively (Fig. 1). We quantified the density, richness and
Toowoon Bay; TA Tanoura; KU Kutsuu and US USA. Settlement choice experiments were conducted at the Yokonami Rinkai Experimental Station (YO; filled circle)

diversity of vagrant assemblages using haphazardly placed GPS-tracked timed swims (Garmin; $\leq 3-\mathrm{m}$ accuracy; 5-s intervals), which allowed distances surveyed to be measured. Surveys were conducted on snorkel at $0-4 \mathrm{~m}$ depth on reefs that were partially exposed to ocean swell (Beck et al. 2014). This survey method allows more accurate detection of richness and diversity of vagrants within temperate reefs than standard belt transects, with comparable accuracy and precision of density estimates (Beck et al. 2014). Macroalgal and non-macroalgal habitats were surveyed for vagrant fishes at seven SE Australian sites and three W Japanese sites separated by $2.5-40 \mathrm{~km}$. 
At each site, tropical fish recruits were surveyed using six, 5-min roaming surveys within each habitat. Surveys were repeated in Australia once yearly in 2011, 2012 and 2014, while Japanese sites were only surveyed in 2013. In total, both habitats were surveyed 126 times in SE Australia (across the three years), and 18 patches of both habitats were surveyed in W Japan. Patches of macroalgal and non-macroalgal reef surveyed for vagrants were haphazardly selected prior to surveys and interspersed to avoid spatial pseudoreplication. Survey interspersion also ensured influences of wave exposure on fish recruitment were comparable between sites and habitats (Beck et al. 2016a). The dominant non-macroalgal or macroalgal habitat cover was classified and recorded for each survey replicate. Macroalgal habitats surveyed in SE Australia comprised Ecklonia radiata, Sargassum spp. and Phyllospora comosa, while E. cava dominated W Japanese reefs. Macroalgal patches surveyed had $>75 \%$ cover and were $25-75 \mathrm{~m}^{2}$ in area. Macroalgal patches surveyed were largely monospecific (i.e. one species of macroalgae comprised $>80 \%$ of the canopy assemblage). Nonmacroalgal reef patches had $<10 \%$ cover of macroalgae and were either barren reef (bare or encrusted covered rock) or covered with low ( $<10 \mathrm{~cm}$ height, with a mean height of $\sim 5 \mathrm{~cm}$ ) ephemeral or turfing Rhodophyta and Phaeophyceae. Frond heights $<10 \mathrm{~cm}$ were considered low relief on the temperate reefs surveyed, where the average frond length of macroalgal patches was $\sim 30-40 \mathrm{~cm}$.

Vagrant fishes encountered within $1 \mathrm{~m}$ either side of the observer were identified to species and their total length estimated visually. To avoid wrongly assigning individuals to a habitat due to the response of a fish to an observer, only individuals found more than $0.5 \mathrm{~m}$ from boundaries of macroalgal and non-macroalgal habitats were recorded (i.e. not near edges). Fishes found on edges of habitat were uncommon $(<1 \%$ of sightings). Individuals were identified as recruits of the present season (i.e. young-of-the-year) or juvenile based on family-specific length-age criteria established by Booth et al. (2007), while dietary preferences were assigned following Froese and Pauly (2015), the IUCN red list of threatened species (V2015.2) and a review of scientific literature (Electronic Supplementary Material, ESM, Table S1). Where known, we assigned trophic groups based on feeding preferences during early life stages and/or within temperate reef habitats. However, we acknowledge that fish dietary preferences are likely to be far more complex than documented and vary substantially between tropical and temperate ecosystems. Tropical vagrant species were defined as those found as breedingaged adults only between the Tropics of Cancer and Capricorn $\left(23^{\circ} 27^{\prime} \mathrm{N}\right.$ and S, respectively), as determined by distribution data from Kuiter (1993); Froese and Pauly (2015) and IUCN red list maps (V2015.2) (ESM Table S1).
All surveys were conducted by the main author (HJB) between 0900 and $1700 \mathrm{hrs}$, when water visibility was $>5 \mathrm{~m}$ and swell was $<1 \mathrm{~m}$.

\section{Abiotic and biotic drivers of recruitment to non- macroalgal and macroalgal habitat}

Factors influencing recruitment of vagrants to macroalgal and non-macroalgal patches were explored in SE Australia during 2014. To test whether macroalgal cover per se influenced tropical fish recruitment to temperate reefs, benthic habitat surveyed (i.e. major temperate macroalgal species and non-macroalgal habitats), species richness and densities of the resident temperate reef fish community (estimated during vagrant species surveys), reef rugosity (structural complexity) and wave exposure were measured in each macroalgal and non-macroalgal reef patch surveyed for vagrant fishes. The extent of benthic habitats surveyed was estimated by recording the proportion of time the surveyor spent over each of the primary benthic habitats (listed below) during surveys. Habitats were categorised either as one of the dominant habitat-forming macroalgae (E. radiata, P. comosa or Sargassum spp.) or as nonmacroalgal habitat (turfing algae or barren rock). Turfing algae was considered to be branching algae with a height $<10 \mathrm{~cm}$, while 'barren' was reef where all branching algae were absent. The macroalgal canopy was typically monospecific in surveyed patches (e.g. of the seven sites surveyed, E. radiata comprised all macroalgal patches at four sites, and one site consisted of only $P$. comosa patches). Moreover, non-macroalgal reef habitat was consistent in $\sim 80 \%$ of survey replicates, with the reef patch consisting of either turfing algae or an expanse of barren reef. Wave exposure was calculated using a fetch-based index (Hill et al. 2010). This measure of exposure divides the sum of the distances to the nearest land along 7.5 rays, measured from the midpoint of survey sites, by the maximum potential exposure (rays were extended to a maximum of $650 \mathrm{~km}$, which is the minimum fetch distance for seas to fully develop). Reef rugosity was averaged over areas within each reef patch (i.e. every ten swim kicks, measured immediately after fish surveys), using the ratio of surface distance to linear distance of a 5-m chain (Risk $1972 ; n=126$ in both macroalgal and non-macroalgal habitats).

\section{Settlement choice of tropical fish larvae: macroalgal versus non-macroalgal habitat}

To test settlement preferences of a common tropical vagrant fish, habitat choice of late-stage larvae of the tropical damselfish $P$. coelestis was assessed within aquarium trials at Yokonami Beach, W Japan (Fig. 1). 
Pomacentrus coelestis was selected as the focal species due to its high abundance (Nakamura et al. 2013); this species is also one of the most common tropical species recruiting to both SE Australian and W Japanese temperate reefs (Booth et al. 2007; Nakamura et al. 2013; Soeparno et al. 2013)

Pomacentrus coelestis larvae were collected by lighttrapping (Fisher and Bellwood 2002) on four consecutive nights in July 2013. Traps were set and collected each evening and morning, respectively. At 2100 hrs on the night of collection, individual $P$. coelestis larvae were released into the middle of $85-\mathrm{L}$ outdoor, rectangular aquaria containing one patch of encrusting algae covered rock and one patch of kelp, E. cava; these habitats were the most common nonmacroalgal and macroalgal habitats in W Japan. Habitat patches were placed at opposite ends of the aquarium, with a similar coverage for each (each habitat covered 11-30\% of aquarium bottom). Habitat choice of $P$. coelestis on nonmacroalgal and macroalgal habitat was recorded at $\sim 0530 \mathrm{hrs}$ for $15 \mathrm{~min}$. An individual fish was considered to have made a choice when it was found $\leq 2 \mathrm{~cm}$ from a habitat for at least $10 \mathrm{~min}$. We conducted 24 settlement trials, with different individuals used in each trial. Between trials, habitats were randomly switched between ends of aquaria to reduce any potential tank effect.

\section{Statistical analyses}

Because the number of survey occasions (3 $\mathrm{yr}$ in SE Australia, 1 yr in W Japan), replicate surveys (126 in SE Australia, 18 in SE Japan) and number of sites (seven in SE Australia, three in $\mathrm{W}$ Japan) differed between regions, vagrant assemblages were separately evaluated within SE Australia and W Japan. To test whether tropical vagrants avoided temperate habitats that were dominated by macroalgae, we compared total vagrant assemblage density (total individuals $\mathrm{m}^{-2}$ ), species richness (total species $\mathrm{m}^{-2}$ ), density and richness of trophic groups, between macroalgal and non-macroalgal habitat (fixed), site (random) and year (SE Australia only, random), using univariate permutation analysis of variance (PERMANOVA), based on Euclidean distances among sample data, type III sums of squares and 9999 permutations under the reduced model (Anderson 2001).

Species and trophic diversity of vagrant assemblages were compared between habitats, and among sites and years (SE Australia only) by $K$-dominance plots. As a diversity measure, $K$-dominance plots better account for species and trophic group evenness than single-value diversity indexes (Lambshead et al. 1983). K-dominance plots were constructed individually for replicate surveys on fourth-root-transformed density data (Clarke and Gorley
2006), cumulatively ranking species and trophic diversity, expressed as a percentage of all species, in decreasing order of density. Fourth-root transformations were used, as recommended by Quinn and Keough (2002), since there were many low and some high fish counts within survey replicates. Pairwise distances between $K$-dominance plots, constructed for each survey using Manhattan distance metrics, were then calculated using DOMDIS (PRIMER v6; Warwick 1986; Clarke 1990; Clarke and Gorley 2006). $K$-dominance curves for species and trophic diversity were then compared between habitats, among years (SE Australia only) and among sites by PERMANOVA, using the same design as for richness and diversity. Trophic groups that were important contributors to dissimilarity of fish assemblages between habitats were identified using the similarity percentages routine (SIMPER; Clarke 1993) and then graphically explored by principal coordinates ordination (PCO) using Spearman's rank correlation. A priori, we decided trophic groups with $\% \bar{\delta}_{i}>10 \%$ were important contributors to overall dissimilarity between habitats, where $\bar{\delta}_{i}$ is the average contribution of the $i$ th trophic group to the overall dissimilarity $[\bar{\delta}]$ between the two habitats. Densities of these trophic groups, identified by SIMPER as important contributors to variance in fish assemblages, were then compared between habitats and among years (SE Australia only), and among sites using PERMANOVA. To conform to the statistical assumption that variances were homogeneous, sites were excluded from trophic analyses where we observed fewer than five individuals belonging to a particular trophic group in each survey year.

All survey data were inspected for homogeneity of variance using the PERMDISP procedure (PRIMER v6), with data $\ln (X+1)$, square- or fourth-root-transformed where required. PERMANOVA was used as it is typically more robust to heterogeneity of variances and assumptions of data normality than parametric analyses (Underwood 1997; Anderson and Walsh 2013). Where the $P$ value of a factor was $>0.25$, it was pooled with the residual (following Underwood 1997). The Monte Carlo $p$ value $[P(\mathrm{mc})]$ was used when the number of unique permutations for a term within an analysis was $<100$ (following Anderson 2001). Significant interactions between factors for all analyses of field parameters were explored using PERMANOVA post hoc pairwise tests.

To determine the abiotic and biotic variables that best predicted difference in vagrant assemblages between macroalgal and non-macroalgal temperate reef habitats, a best-fit distance-based linear model (DISTLM) was used. The DISTLM focused on habitat variables measured during surveys of vagrant fishes in SE Australia during 2014, which were: trophic preference of temperate fish assemblages, reef complexity, extent of macroalgae, primary 
macroalgal species, overall extent of non-macroalgal habitat, extent of each non-macroalgal habitat and wave exposure. This analysis was conducted using Bray-Curtis similarity measures on fourth-root-transformed vagrant abundance for all sites, habitats and species in 2014 in SE Australia (Clarke and Gorley 2006). We calculated Akaike's information criterion $\left(\mathrm{AIC}_{\mathrm{c}}\right)$ with a maximum of ten variables and using 9999 permutations. The most parsimonious model was the combination of environmental variables with $\mathrm{AIC}_{\mathrm{c}}$ within two units of the overall best solution with the least number of variables (Anderson et al. 2008). Environmental data were checked for multicollinearity and dispersion using draftsmen plots, $\ln (X+1)$ or square-root-transformed where required and then normalised prior to analysis. Relationships among environmental data (post-transformation) were also checked for linearity prior to analysis. Factors best explaining variance in SE Australian vagrant communities were graphically explored by PCO and Spearman rank correlation.

To test whether tropical fishes associated with a particular non-macroalgal habitat more strongly, the density, richness and diversity of tropical fish assemblages were compared between patches of barren reef (bare rock and sea urchin barren) or turfing algae-dominated reef. These variables were also compared between patches of reef where Ecklonia, Phyllospora and Sargassum spp. dominated. Due to the unbalanced replication of these habitats across survey years and locations, density, richness and diversity data were pooled within each country prior to analysis. Density, richness and diversity ( $K$-dominance) were analysed using PERMANOVA following the protocol detailed above.

To determine whether vagrant habitat associations were caused by active preference at settlement, the proportion of $P$. coelestis that settled into the macroalgal and nonmacroalgal habitats was compared by binomial tests, treating the probability of either outcome by chance as $50 \%$. These proportional data were normalised by squareroot transformation prior to analysis.

The level of significance was set at $P<0.05$ for all analyses. Field data were analysed using PRIMER v6 with PERMANOVA + extension, and SPSS v20 was used to analyse settlement trial data.

\section{Results}

\section{Tropical fish recruits in non-macroalgal and macroalgal temperate rocky reef}

\section{Overall assemblages}

A total of 3033 vagrant tropical fishes, from 36 species in seven families, were surveyed within SE Australia (27 species and six families) and W Japan (20 species and five families; ESM Table S1). There was a $44 \%$ overlap in species between SE Australia and W Japan; these species belonged to the families Pomacentridae (damselfishes, 11 species), Acanthuridae (surgeonfishes; ten species), Chaetodontidae (butterflyfishes; seven species), Labridae (wrasses; four species) and Zanclidae (Moorish idol).

Vagrant densities and species richness were over seven times greater in non-macroalgal than macroalgal reef habitats in both regions (PERMANOVA; species richness for both countries, $P \leq 0.007$; density in W Japan, $P<0.001$; Fig. 2; Table 1). Vagrants were also significantly more abundant in non-macroalgal than macroalgal habitat in all three years studied in SE Australia (Pairwise test; $P \leq 0.002$ for all years), despite an interaction between habitat and year (PERMANOVA; $P=0.02$; Table 1). Moreover, vagrants were more diverse in nonmacroalgal than macroalgal habitats in SE Australia and $\mathrm{W}$ Japan (PERMANOVA; $P \leq 0.001$ in both countries; Table 1). There was no significant interaction between habitat and all other factors within the model for species diversity and species richness in either country, or density in W Japan $(P>0.15$; Table 1). Mean (SD) area searched within non-macroalgal and macroalgal patches per site was $197.93(78.12)$ and $175.25(63.48) \mathrm{m}^{2}$, respectively $(\mathrm{n}=6$ surveys in each habitat per site).

Of the 36 species observed, 17 were more often in nonmacroalgal habitat than expected by chance (Binomial test; $P<0.02$ for all species; Fig. 3; ESM Table S1). Moreover, 15 species were exclusively found in non-macroalgal habitat although sample numbers were too low for analysis $(n<5)$. There was no difference in frequencies of Ctenochaetus striatus, Naso unicornis or Canthigaster rivulata (Binomial test; $P>0.05$ ) between macroalgal and nonmacroalgal habitat. Siganus fuscescens was observed in significantly greater frequencies within macroalgal habitat (Binomial test; $P<0.0001$ ).

\section{Trophic assemblage and individual trophic groups}

Planktivores were the most abundant trophic group within SE Australia (56\%) and W Japan (64\%); assemblages also included herbivores (31\% Australia; $18 \%$ Japan), benthivores (5\% Australia; 10\% Japan), omnivores (4\% Australia; 9\% Japan) and ectoparasite feeders and piscivores (both $<1 \%$, Australia only). The diversity and richness of trophic groups were significantly greater in non-macroalgal than macroalgal habitats in both SE Australia and W Japan (Table $1 ; P \leq 0.001$ ). There were no significant interactions between habitat and any other variable for either metric in either country ( $P \geq 0.15$ for remaining terms in models).

PCO partitioned trophic assemblages between nonmacroalgal and macroalgal habitats along PCO axis 1, 

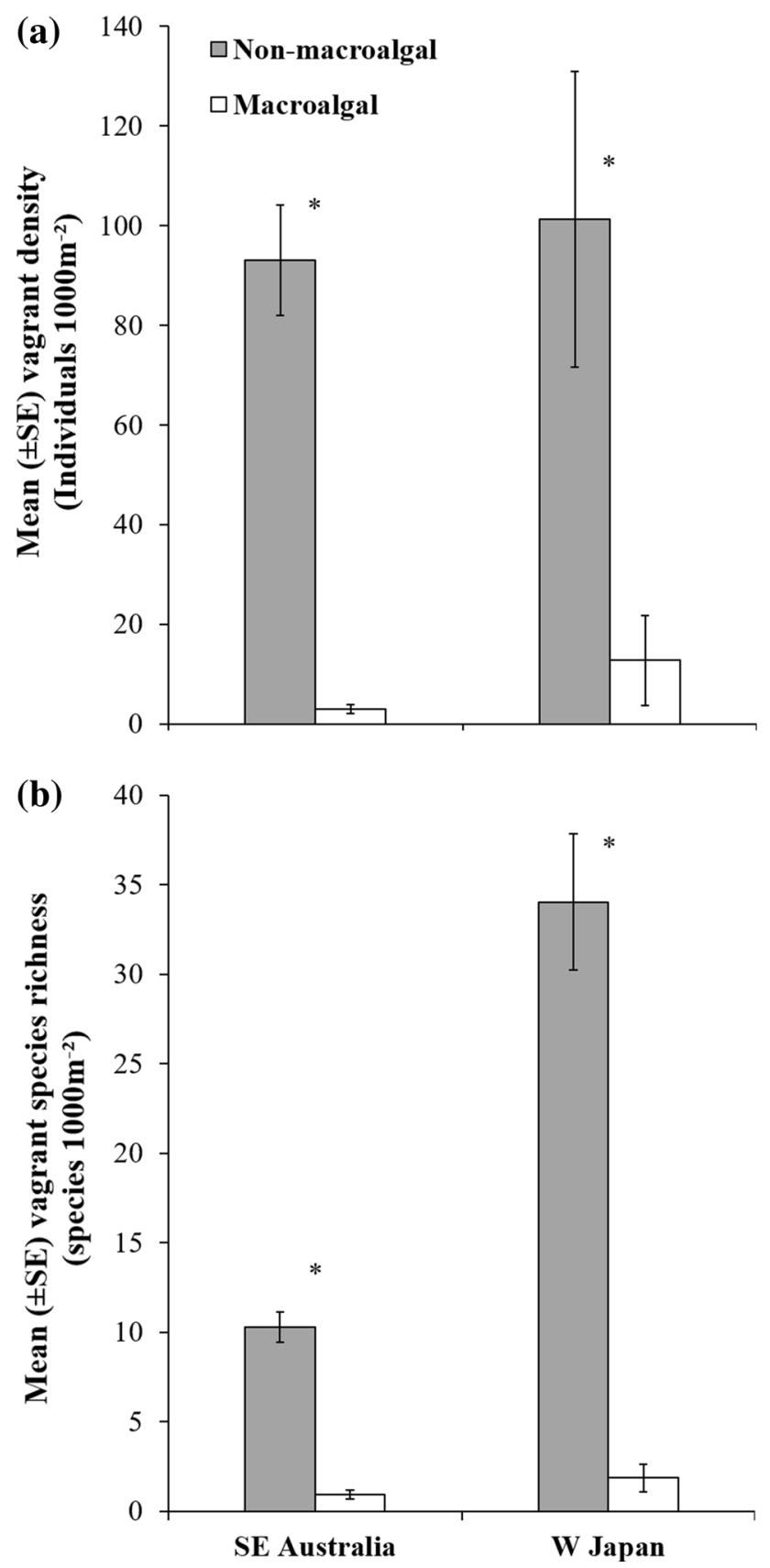

Fig. 2 Mean $( \pm \mathrm{SE})$ total density (a) and species richness (b) of tropical vagrant fishes within non-macroalga1 (grey bars) and macroalga1 (white bars) reef habitats within south-eastern (SE) Australia and western (W) Japan. $n=126,5$-min-timed swims per habitat, pooled across three years for SE Australia, and $n=18$ per habitat for one recruitment season in W Japan

explaining 71.2 and $65.9 \%$ of variance in trophic assemblages within SE Australia and $\mathrm{W}$ Japan, respectively (Fig. 4). Planktivores and herbivores in SE Australia and W Japan, as well as benthivores and omnivores in W Japan, primarily accounted for differences in assemblages between non-macroalgal and macroalgal habitats (SIMPER; $\% \bar{\delta}_{i}>10 \%$ ). These trophic groups were positively correlated with non-macroalgal reefs along PCO axis 1 within their respective countries (Spearman correlation; $P<0.05, \mathrm{r}_{\mathrm{s}}>0.48$; Fig. 4).

Planktivores and herbivores were in greater densities in non-macroalgal than macroalgal habitat in SE Australia (Pseudo- $F_{1,90}=96.8, \quad P=0.01$ and Pseudo- $F_{1,170}=$ 214.4, $P<0.001$ for planktivores and herbivores, respectively; Figs. 3, 4). In W Japan, densities of omnivores [Pseudo- $\left.F_{1,18}=239.1, \quad P(\mathrm{mc})=0.04\right]$ and herbivores [Pseudo- $\left.F_{1,30}=20.33, P(\mathrm{mc})=0.04\right]$ were significantly greater in non-macroalgal than macroalgal reefs. Densities of planktivores were significantly greater in non-macroalgal habitat in W Japanese sites of $\mathrm{KA}[P(\mathrm{mc})=0.0001]$ and USA $[P(\mathrm{mc})=0.001]$, but not TA $[P(\mathrm{mc})=0.22]$. Benthivores were in significantly greater densities on nonmacroalgae reef at TA $[P(\mathrm{mc})=0.02]$, but not USA $[P(\mathrm{mc})=0.14]$. Influence of habitat on planktivore and benthivore density depended on site in W Japan [planktivores, Pseudo- $F_{2,30}=4.95, P(\mathrm{mc})=0.01$; benthivores, Pseudo- $\left.F_{2,20}=5.34, \quad P(\mathrm{mc})=0.03\right]$. All interactions involving 'habitat' type with site and/or year (SE Australia only) not reported here were non-significant in both countries.

\section{Abiotic and biotic influences on tropical fish recruitment}

Of the environmental factors measured, the proportion of barren reef surveyed best predicted differences in the composition of vagrant fish assemblages (17.8\%; Fig. 5; ESM Tables S2, S3). The composition of vagrant assemblages positively corresponded to the extent of barren reef (where branching algae were absent) covered during surveys (Spearman rank; $r_{s}=0.52, P=0.001$ ). The density and richness of the vagrant assemblages significantly increased with increasing extent of barren surveyed (density: $r_{s}=0.46 ; t=7.25 ; P<0.001$; richness: $r_{s}=0.27$; $t=2.56 ; P=0.006)$. The best combination of explanatory variables (AICc $=635.14$ ) also included the density of the overall temperate fish assemblage (13.7\%), but this failed to explain variance in vagrant assemblages, since the overall temperate fish assemblages also positively corresponded with non-macroalgal reefs (Fig. 5).

Of the non-macroalgal habitats surveyed in SE Australia, the density (Pseudo- $F_{1,124}=7.32, P=0.007$ ), richness (Pseudo- $F_{1,124}=6.33, P=0.01$ ) and diversity (Pseudo- $F_{1,124}=4.91, P=0.04$ ) of tropical fishes were significantly greater on patches of reef where barrens dominated than where turfing algae were dominant. Tropical fish richness, diversity and density did not significantly differ between patches of $E$. radiata, $P$. comosa or Sargassum spp. $(P<0.05$ for all three variables $)$. Nonmacroalgal reefs surveyed in $\mathrm{W}$ Japan were all dominated 
by turfing algae, while macroalgal patches surveyed were dominated by $E$. cava.

\section{Settlement of tropical fish larvae into macroalgal versus non-macroalgal habitat}

A significant proportion $(87.5 \%)$ of $P$. coelestis larvae settled into the non-macroalgal reef (Binomial test, $P<0.001$ ), while only three of the 24 individuals settled into the macroalgal habitat. No individual changed habitat choice between sunrise ( $\sim 0530 \mathrm{hrs})$ and $0800 \mathrm{hrs}$.

\section{Discussion}

The ability of tropical reef fishes to shift poleward with ocean warming may be strongly dependant on the availability of suitable reef habitats at temperate latitudes (Feary et al. 2014). Here we show that temperate macroalgal patches may strongly inhibit the recruitment of many tropical reef fish, since the overall density of assemblages, trophic and taxonomic diversity and species richness of new recruit and early juvenile tropical vagrants were greater within non-macroalgal than macroalgal patches of temperate SE Australian and W Japanese reefs. This result was also consistent over three recruitment seasons in SE Australia. Our results suggest that, at least in temperate reefs partially exposed to swell, macroalgal cover leads to spatial patchiness in recruitment of many tropical fishes,
Fig. 3 Mean $( \pm$ SE) total density of tropical vagrant fishes within non-macroalga1 (grey bars) and macroalga1 reef habitats (white bars) within (a) south-eastern (SE) Australia and (b) western (W) Japan. Species sorted by dietary preference; $H$ herbivore, $B$ benthivore, $P l$ planktivore, $O$ omnivore, $D$ detritivore, $E$ ectoparasite feeder and $P$ piscivore

potentially inhibiting colonisation of some species (Bates et al. 2014).

The extent of macroalgae on surveyed temperate reefs best explained variance in the density, richness, diversity and trophic composition of vagrant fish assemblages across our study locations; vagrants positively associated with reefs without any branching algae. Despite potential effects of temperate reef fishes on recruitment of vagrant tropical reef fishes (e.g. heightened competition, predation and grazing; Bates et al. 2014; Beck 2014; Vergés et al. 2014), the abundance and richness of temperate fish assemblages, either in total or in specific trophic groups, failed to explain the observed strong association of tropical fishes with nonmacroalgal reefs. Notably, densities of temperate reef fishes were positively associated with non-macroalgal habitats, which supported earlier findings by Curley et al. (2002). Hence, despite use of the same habitats, temperate fishes that also associate with reef lacking macroalgae did not appear to exclude tropical fishes from recruiting. However, we cannot discount a role for competition and predation between vagrants and temperate species postsettlement, and we did not evaluate the extent that these
Table 1 Results of PERMANOVAs testing for differences in density, richness and diversity ( $K$-dominance) of tropical reef fish assemblages among habitats $(\mathrm{H}$; macroalgals versus non-macroalgals reef patches), sites (S) and years (Y; Australia only) within temperate reefs of SE Australia and W Japan

\begin{tabular}{|c|c|c|c|c|c|c|c|c|c|}
\hline \multicolumn{10}{|l|}{ Effects of variable } \\
\hline \multicolumn{4}{|l|}{ Habitat $(\mathrm{H})$} & \multicolumn{6}{|c|}{ Other factors ( $P$ values) } \\
\hline Parameter & Pseudo- $F$ & $D f$ & $P$ & $S$ & $\begin{array}{l}S \times \\
H\end{array}$ & $Y$ & $Y \times H$ & $Y \times S$ & $\begin{array}{l}S \times \\
Y \times \\
H\end{array}$ \\
\hline \multicolumn{10}{|l|}{ SE Australia } \\
\hline Density & 28.03 & 1.210 & $<0.001$ & 0.04 & 0.09 & 0.01 & 0.02 & 0.09 & 0.14 \\
\hline Species richness & 179.04 & 1.210 & $<0.001$ & 0.17 & 0.35 & 0.15 & 0.32 & 0.005 & 0.15 \\
\hline Species diversity & 61.17 & 1.210 & $<0.001$ & $\mathbf{0 . 0 3}$ & 0.33 & 0.07 & 0.15 & 0.07 & 0.42 \\
\hline Trophic richness & 64.10 & 1.210 & $<0.001$ & 0.16 & 0.33 & 0.09 & 0.22 & 0.01 & 0.29 \\
\hline Trophic diversity & 171.9 & 1.210 & 0.001 & 0.0001 & 0.34 & 0.05 & 0.13 & 0.19 & 0.47 \\
\hline \multicolumn{10}{|l|}{ W Japan } \\
\hline Density & 95.4 & 1.30 & $\mathbf{0 . 0 0 1}^{\mathrm{a}}$ & 0.12 & 0.75 & - & - & - & - \\
\hline Species richness & 154.0 & 1.30 & $0.007^{\mathrm{a}}$ & 0.27 & 0.46 & - & - & - & - \\
\hline Species diversity & 54.67 & 1.30 & $\mathbf{0 . 0 0 1}^{\mathrm{a}}$ & 0.52 & 0.88 & - & - & - & - \\
\hline Trophic richness & 1060 & 1.30 & $\mathbf{0 . 0 0 1}^{\mathrm{a}}$ & 0.45 & 0.99 & - & - & - & - \\
\hline Trophic diversity & 6.82 & 1.30 & $\mathbf{0 . 0 0 1}^{\mathrm{a}}$ & 0.45 & 0.99 & - & - & - & - \\
\hline
\end{tabular}

Factors were pooled with the residual when $P>0.25$, according to Underwood (1997)

Bold $P$ values indicate a significant result of $P<0.05$. ${ }^{\text {a }}$ denotes $P(\mathrm{mc})$, used where the number of unique permutations for a factor was $<100$, following Anderson (2001) 

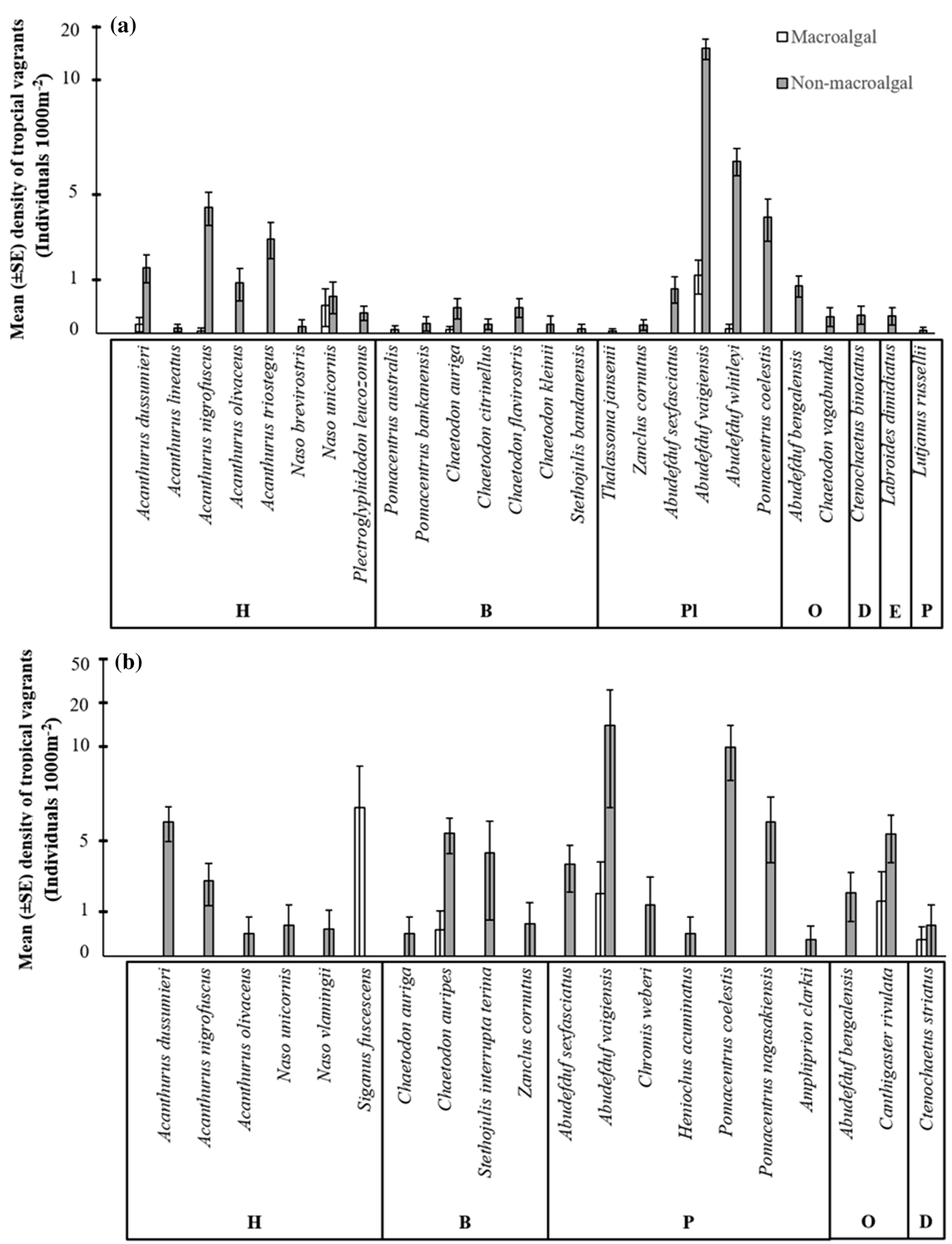

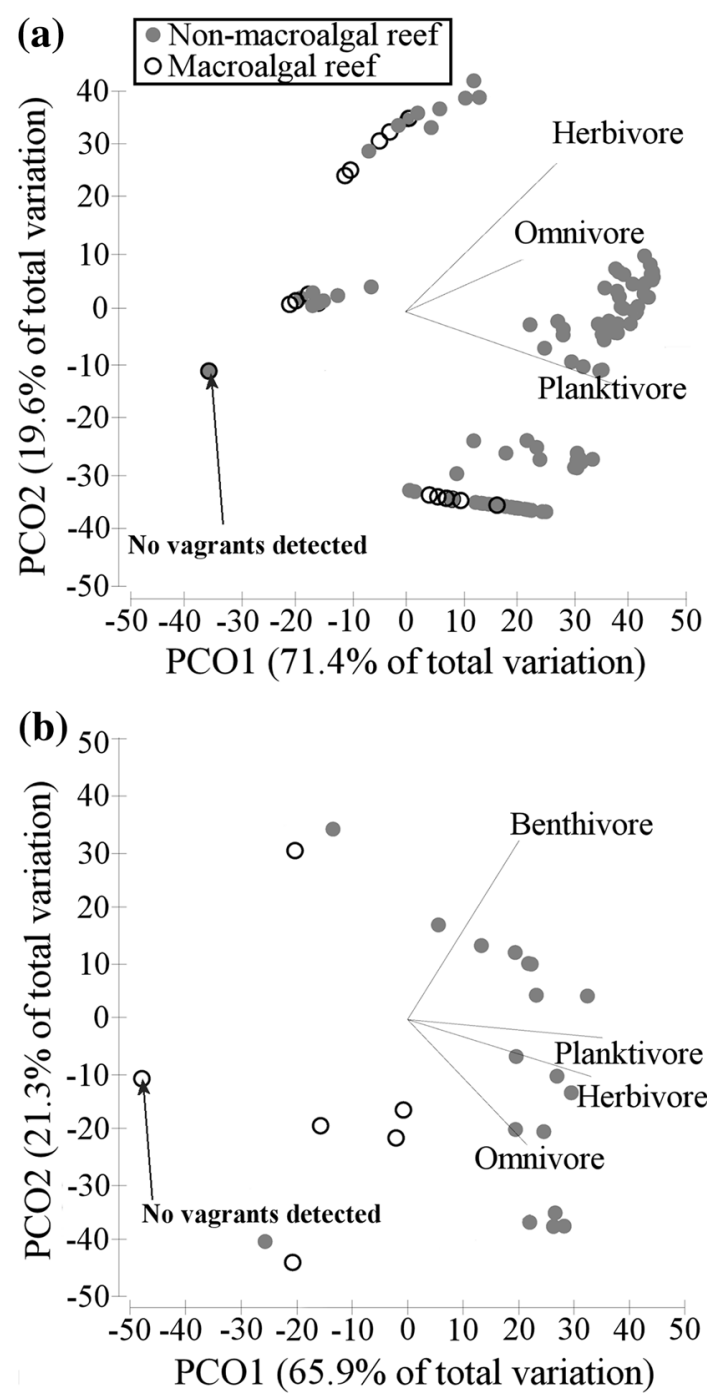

Fig. 4 Principal coordinate ordination (PCO) of tropical vagrant trophic groups within macroalgal and non-macroalgal reef habitats of (a) SE Australia and (b) W Japan. Overlaid vectors indicate the primary groups responsible for division of sites along PCO axis 1, determined by SIMPER analysis. Arrows denote replicate surveys where no vagrants were detected: $n=110$ and 23 in macroalgal and non-macroalgal patches in SE Australia, respectively, and $n=13$ in macroalgae in W Japan. In total, $n=126$ and 18 replicate surveys were conducted in both habitats within SE Australia and W Japan, respectively

interactions may determine recruitment. Moreover, it may be possible that some temperate species facilitate recruitment of tropical reef fishes. For instance, the tropical planktivores Abudefduf vaigiensis and A. whitleyi, and grazers Acanthurus dussumieri, A. olivaceus and A. nigrofuscus, were observed schooling with temperate and subtropical fishes with similar dietary preferences (HJ Beck, personal observation). Such schooling behaviour may promote recruitment success by reducing predation risk and enhancing foraging success (Feary et al. 2014). Influences of native species on vagrant recruitment could be assessed

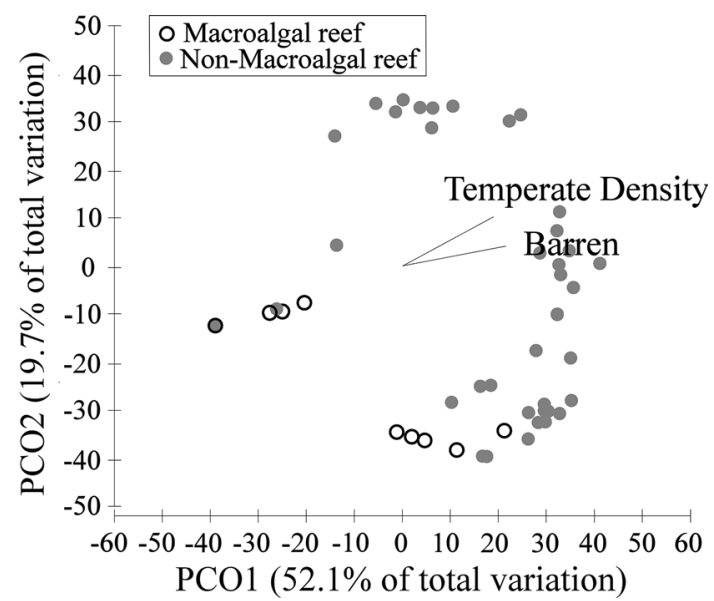

Fig. 5 Principal coordinate ordination of tropical vagrant fish species within macroalgal (open markers) and non-macroalgal (grey markers) reef habitats in SE Australia, surveyed during 2014. Vectors display the environmental correlates that best explained variance in fish assemblage data, as determined by DISTLM; Barren = extent of barrens; temperate density $=$ overall density of temperate fishes. $n=34$ and 5 in macroalgal and non-macroalgal patches in SE Australia, respectively, and $n=13$ in macroalgae in W Japan. In total, $n=42$ replicate surveys were conducted in both habitats

using manipulative experiments, where temperate reef communities are modified to test specific hypotheses. For instance, influences of temperate piscivorous fishes on vagrant population dynamics and behaviours may be tested by studying vagrants inside marine parks, where predator densities are typically high, and where predator populations are depleted by fishing (Beck et al. 2016b).

Structural differences between areas lacking macroalgal habitat and macroalgal reef patches may be vital in determining tropical fish recruitment success. For example, there is a substantial literature showing that structurally stable tropical reef habitats, predominantly scleractinian coral communities, are an important habitat in which many tropical fishes will settle and recruit (Wilson et al. 2006; Pratchett et al. 2011). Such habitat-associated recruitment may be due to habitat structure, with stable and topographically complex reef often better mediating negative interactions with residents (Friedlander and Parrish 1998; Beukers and Jones 1998; Almany 2004; Gratwicke and Speight 2005; Wilson et al. 2010) and lessening effects of physical stressors, such as wave action (Johansen et al. 2007, 2008). Stable reef habitats may also require less energy for marine organisms to associate with than nonstable, moving macroalgae-dominated reef. Abrasion caused by moving kelp may even exclude marine organisms from algal forests (Velimirov and Griffiths 1979; Connell 2003; Gagnon et al. 2004). Nevertheless, macroalgal movement did not appear to influence habitat choice, at least for $P$. coelestis, since this species also 
avoided macroalgae in the aquarium experiment where water/macroalgal movement was minimal. Open habitats, such as non-macroalgal reefs, also potentially increase visibility of predators and prey's ability to escape attacks compared to dense habitats such as macroalgal patches that can conceal predators and block escape efforts. Such avoidance of dense macroalgae has been found for marine invertebrates (Konar and Estes 2003; Gagnon et al. 2003) and proposed for tropical reef fishes (Hoey 2010; Hoey and Bellwood 2011). Moreover, chemical odours released from macroalgae may deter recruitment of many tropical reef fishes, as found on some coral reefs (Lecchini et al. 2013; Dixson et al. 2014; but see Lecchini et al. 2007). We may discount potential influences of observer error from explaining the spatial patterns of fish recruitment detected, since most tropical species surveyed were non-cryptic and brightly coloured, so were easily observed, even when associated with macroalgae (HJ Beck, personal observation). Moreover, the cryptic species Siganus fuscescens was clearly identifiable, with individuals more often found in macroalgae, suggesting that detected patterns of recruitment were not a sampling artefact.

Although our study applies to the dominant vagrant species, temperate macroalgae may still provide important recruitment habitat for some tropical fishes, such as those that associate with tropical macroalgae. For instance, the rabbitfish S. fuscescens, a species whose close relative commonly recruits to macroalgae (Sargassum spp.) on coral reefs (Hoey et al. 2013), was observed associating exclusively with the temperate macroalgae $E$. cava in our study. Such association may be due to food availability, as $S$. fuscescens has been observed grazing E. cava on Japanese reefs (Masuda et al. 2000).

Our study focused on the dominant benthic habitats in coastal reefs partially exposed to swell, but habitat associations of tropical fishes may differ in other temperate coastal environments. For instance, since highly embayed temperate reefs are recruitment hotspots for many tropical fishes (Beck et al. 2016a), some temperate estuaries may offer suitable habitat for tropical fish to recruit. For example, within well-flushed estuaries along the SE Australian coast, extensive seagrass meadows may facilitate tropical fish recruitment, since seagrass is often an important recruitment habitat for many tropical fishes within their tropical range (e.g. Nagelkerken et al. 2000).

The active choice of non-macroalgal reef by settling $P$. coelestis larvae suggests that in situ associations of tropical vagrants with non-macroalgal reef, at least for this species, may reflect settlement preferences rather than higher postrecruitment mortality on macroalgal reefs or post-settlement movement between habitats. Moreover, given the preference of $P$. coelestis for rubble habitats in coral reefs (Öhman et al. 1998) and other temperate regions (e.g.
Wilson et al. 2010), this species may seek similar physical habitat properties, regardless of the geological origin of the reef and latitude. Certainly, further small-scale experiments are required to disclose the process underlying habitat associations of a wider range of tropical fishes in temperate reefs and habitat conditions. An understanding of cues driving associations would also be valuable in predicting important reef habitats for shifting tropical fishes, which may include olfactory, auditory and/or visual cues (Kingsford et al. 2002; Lecchini et al. 2005; Wright et al. 2005).

Our results suggest that distribution of temperate macroalgal communities in thermally marginal temperate reefs should be considered when predicting where and when many tropical fishes may colonise with ongoing ocean warming. Such strong association of many recruiting tropical fishes with non-macroalgal habitat suggests that, at least for the dominant species, human-driven changes in temperate macroalgal assemblages may influence colonisation. An interesting hypothesis stemming from our results is that retraction of kelp under climate change scenarios may facilitate vagrant expansion poleward. Changes in macroalgal communities with potential to influence tropical fish colonisation may also arise from water pollution and increasing grazing pressure (Schiel et al. 2004; Ling 2008; Tait and Schiel 2011; Vergés et al. 2014). However, to more accurately determine how macroalgae influences poleward redistribution of tropical fishes, we require an accurate understanding of larval supply, settlement rates and survivorship of tropical fishes on temperate reefs with varying levels of macroalgal cover (e.g. Bates et al. 2014). Moreover, impacts of macroalgae on tropical species redistribution may be better understood by studying how temperate and tropical macroalgae differentially influence tropical fish recruitment. As there are many species of tropical fishes that use habitats other than coral reefs at tropical latitudes, including seagrasses, mangroves and sponges, the potential for similar temperate benthic communities to support recruitment of these species also needs to be explored. Through a more thorough understanding of interactions between tropical fishes and temperate habitats, management strategies may be effectively designed to alleviate undesirable impacts associated with the tropicalization of temperate reefs.

Acknowledgements HJB gratefully acknowledges funding from the Sydney Institute of Marine Science (SIMS) Doctoral Fellowship Program, and the University of Technology, Sydney. DAF was funded by the University of Technology, Sydney under the Chancellor's Postdoctoral Fellowship scheme. We appreciate the field assistance and advice from B. Curley, W. Figueira, R. Suzuki, K. Tose and B. Yui, and thank A. Fowler for helpful reviews of the manuscript. Animal ethics approval for the research was granted by the University of Technology Sydney (UTS) Animal Care and Ethics Committee 
(ACEC) (Permit 2011-036A). This is contribution 197 of the Sydney Institute of Marine Science.

\section{References}

Almany GR (2004) Differential effects of habitat complexity, predators and competitors on abundance of juvenile and adult coral reef fishes. Oecologia 141:105-113

Anderson MJ (2001) A new method for non-parametric multivariate analysis of variance. Austral Ecol 26:32-46

Anderson MJ, Walsh DC (2013) PERMANOVA, ANOSIM, and the mantel test in the face of heterogeneous dispersions: what null hypothesis are you testing? Ecol Monogr 83:557-574

Anderson MJ, Gorley RN, Clarke K (2008) PERMANOVA + for PRIMER: guide to software and statistical methods. PRIMER-E, Plymouth, UK

Bates AE, Barrett NS, Stuart-Smith RD, Holbrook NJ, Thompson PA, Edgar GJ (2014) Resilience and signatures of tropicalization in protected reef fish communities. Nat Clim Chang 4:62-67

Beck HJ (2014) Tropical fish recruitment success varies among temperate reef habitats, potentially impacting their range expansion. Ph.D. thesis, University of Technology, Sydney, 156pp

Beck HJ, Feary DA, Figueira WF, Booth DJ (2014) Assessing rangeshifts of tropical reef fishes: a comparison of belt transect and roaming underwater census methods. Bull Mar Sci 90:705-721

Beck HJ, Feary DA, Nakamura Y, Booth DJ (2016a) Wave-sheltered embayments are recruitment hotspots for tropical fishes on temperate reefs. Mar Ecol Prog Ser 546:197-212

Beck HJ, Feary DA, Fowler AM, Madin EM, Booth DJ (2016b) Temperate predators and seasonal water temperatures impact feeding of a range expanding tropical fish. Mar Biol 163:1-14

Beukers JS, Jones GP (1998) Habitat complexity modifies the impact of piscivores on a coral reef fish population. Oecologia 114:50-59

Booth DJ, Figueira WF, Gregson MA, Brown L, Beretta G (2007) Occurrence of tropical fishes in temperate southeastern Australia: role of the East Australian Current. Estuar Coast Shelf Sci $72: 102-114$

Burrows MT, Schoeman DS, Richardson AJ, Molinos JG, Hoffmann A, Buckley LB, Moore PJ, Brown CJ, Bruno JF, Duarte CM (2014) Geographical limits to species-range shifts are suggested by climate velocity. Nature 507:492-495

Cheung WW, Lam VW, Sarmiento JL, Kearney K, Watson R, Pauly D (2009) Projecting global marine biodiversity impacts under climate change scenarios. Fish Fish 10:235-251

Cheung WW, Lam VW, Sarmiento JL, Kearney K, Watson R, Zeller D, Pauly D (2010) Large-scale redistribution of maximum fisheries catch potential in the global ocean under climate change. Glob Chang Biol 16:24-35

Clarke KR (1990) Comparisons of dominance curves. J Exp Mar Bio Ecol 138:143-157

Clarke KR (1993) Non-parametric multivariate analyses of changes in community structure. Austral Ecol 18:117-143

Clarke KR, Gorley RN (2006) PRIMER v6: user manual/tutorial. Plymouth Marine Laboratory, Plymouth, UK

Connell SD (2003) Negative effects overpower the positive of kelp to exclude invertebrates from the understorey community. Oecologia 137:97-103

Curley BG, Gillanders BM, Kingsford MJ (2002) Spatial and habitatrelated patterns of temperate reef fish assemblages: implications for the design of marine protected areas. Mar Freshw Res 53:1197-1210

Dixson DL, Abrego D, Hay ME (2014) Chemically mediated behavior of recruiting corals and fishes: a tipping point that may limit reef recovery. Science 345:892-897
Evans RD, Wilson SK, Field SN, Moore JA (2014) Importance of macroalgal fields as coral reef fish nursery habitat in north-west Australia. Mar Biol 161:599-607

Feary DA, Pratchett MS, Emslie MJ, Fowler AM, Figueira WF, Luiz OJ, Nakamura Y, Booth DJ (2014) Latitudinal shifts in coral reef fishes: why some species do and others do not shift. Fish Fish 15:593-615

Figueira WF, Booth DJ (2010) Increasing ocean temperatures allow tropical fishes to survive overwinter in temperate waters. Glob Chang Biol 16:506-516

Figueira WF, Biro P, Booth DJ, Valenzuela VC (2009) Performance of tropical fish recruiting to temperate habitats: role of ambient temperature and implications of climate change. Mar Ecol Prog Ser 384:231-239

Fisher R, Bellwood D (2002) The influence of swimming speed on sustained swimming performance of late-stage reef fish larvae. Mar Biol 140:801-807

Friedlander AM, Parrish JD (1998) Habitat characteristics affecting fish assemblages on a Hawaiian coral reef. J Exp Mar Bio Ecol 224:1-30

Froese R, Pauly D (2015) FishBase. http://www.fishbase.org. Accessed 08/2014

Frusher SD, Hobday AJ, Jennings SM, Creighton C, D'Silva D, Haward M, Holbrook NJ, Nursey-Bray M, Pecl GT, van Putten IE (2014) The short history of research in a marine climate change hotspot: from anecdote to adaptation in south-east Australia. Rev Fish Biol Fish 24:593-611

Gagnon P, Wagner G, Himmelman JH (2003) Use of a wave tank to study the effects of water motion and algal movement on the displacement of the sea star Asterias vulgaris towards its prey. Mar Ecol Prog Ser 258:125-132

Gagnon P, Himmelman JH, Johnson LE (2004) Temporal variation in community interfaces: kelp-bed boundary dynamics adjacent to persistent urchin barrens. Mar Biol 144:1191-1203

Gaylord B, Gaines SD (2000) Temperature or transport? Range limits in marine species mediated solely by flow. Am Nat 155:769-789

Gratwicke B, Speight MR (2005) The relationship between fish species richness, abundance and habitat complexity in a range of shallow tropical marine habitats. J Fish Biol 66:650-667

Harley CD, Randall Hughes A, Hultgren KM, Miner BG, Sorte CJB, Thornber CS, Rodriguez LF, Tomanek L, Williams SL (2006) The impacts of climate change in coastal marine systems. Ecol Lett 9:228-241

Hellmann JJ, Prior KM, Pelini SL (2012) The influence of species interactions on geographic range change under climate change. Ann N Y Acad Sci 1249:18-28

Hill JK, Collingham YC, Thomas CD, Blakeley DS, Fox R, Moss D, Huntley B (2001) Impacts of landscape structure on butterfly range expansion. Ecol Lett 4:313-321

Hill NA, Pepper AR, Puotinen ML, Hughes MG, Edgar GJ, Barrett NS, Stuart-Smith RD, Leaper R (2010) Quantifying wave exposure in shallow temperate reef systems: applicability of fetch models for predicting algal biodiversity. Mar Ecol Prog Ser 417:83-95

HilleRisLambers J, Harsch MA, Ettinger AK, Ford KR, Theobald EJ (2013) How will biotic interactions influence climate changeinduced range shifts? Ann N Y Acad Sci 1297:112-125

Hoey AS (2010) Size matters: macroalgal height influences the feeding response of coral reef herbivores. Mar Ecol Prog Ser 411:299-302

Hoey AS, Bellwood DR (2011) Suppression of herbivory by macroalgal density: a critical feedback on coral reefs? Ecol Lett $14: 267-273$

Hoey AS, Brandl SJ, Bellwood DR (2013) Diet and cross-shelf distribution of rabbitfishes (f. Siganidae) on the northern Great 
Barrier Reef: implications for ecosystem function. Coral Reefs 32:973-984

Honnay O, Verheyen K, Butaye J, Jacquemyn H, Bossuyt B, Hermy M (2002) Possible effects of habitat fragmentation and climate change on the range of forest plant species. Ecol Lett 5:525-530

Johansen JL, Fulton CJ, Bellwood DR (2007) Avoiding the flow: refuges expand the swimming potential of coral reef fishes. Coral Reefs 26:577-583

Johansen J, Bellwood D, Fulton C (2008) Coral reef fishes exploit flow refuges in high-flow habitats. Mar Ecol Prog Ser 360:219-226

Keith SA, Herbert RJ, Norton PA, Hawkins SJ, Newton AC (2011) Individualistic species limitations of climate-induced range expansions generated by meso-scale dispersal barriers. Divers Distrib 17:275-286

Kingsford MJ, Leis JM, Shanks A, Lindeman KC, Morgan SG, Pineda J (2002) Sensory environments, larval abilities and local self-recruitment. Bull Mar Sci 70:309-340

Konar B, Estes JA (2003) The stability of boundary regions between kelp beds and deforested areas. Ecology 84:174-185

Kuiter RH (1993) Coastal fishes of south-eastern Australia. University of Hawaii Press, Honolulu

Lambshead PJ, Platt HM, Shaw KM (1983) The detection of differences among assemblages of marine benthic species based on an assessment of dominance and diversity. J Nat Hist $17: 859-874$

Lecchini D, Shima J, Banaigs B, Galzin R (2005) Larval sensory abilities and mechanisms of habitat selection of a coral reef fish during settlement. Oecologia 143:326-334

Lecchini D, Osenberg CW, Shima JS, St Mary CM, Galzin R (2007) Ontogenetic changes in habitat selection during settlement in a coral reef fish: ecological determinants and sensory mechanisms. Coral Reefs 26:423-432

Lecchini D, Waqalevu VP, Parmentier E, Radford CA, Banaigs B (2013) Fish larvae prefer coral over algal water cues: implications of coral reef degradation. Mar Ecol Prog Ser 475:303-307

Ling SD (2008) Range expansion of a habitat-modifying species leads to loss of taxonomic diversity: a new and impoverished reef state. Oecologia 156:883-894

Mair L, Hill JK, Fox R, Botham M, Brereton T, Thomas CD (2014) Abundance changes and habitat availability drive species' responses to climate change. Nat Clim Chang

Masuda H, Tsunoda T, Hayashi Y, Nishio S, Mizui H, Horiuchi S, Nakayama Y (2000) Decline of afforested Ecklonia cava community by grazing of herbivorous fish Siganus fuscescens. Fish Eng 37:135-142

Nagelkerken I, Van der Velde G, Gorissen MW, Meijer GJ, Van't Hof T, Den Hartog C (2000) Importance of mangroves, seagrass beds and the shallow coral reef as a nursery for important coral reef fishes, using a visual census technique. Estuar Coast Shelf Sci 51:31-44

Nakamura Y, Feary DA, Kanda M, Yamaoka K (2013) Tropical fishes dominate temperate reef fish communities within western Japan. PLoS One 8:e81107

Öhman MC, Munday PL, Jones GP, Caley MJ (1998) Settlement strategies and distribution patterns of coral-reef fishes. J Exp Mar Bio Ecol 225:219-238

Pereira HM, Leadley PW, Proença V, Alkemade R, Scharlemann JP, Fernandez-Manjarrés JF, Araújo MB, Balvanera P, Biggs R, Cheung WW (2010) Scenarios for global biodiversity in the 21st century. Science 330:1496-1501

Pinsky ML, Worm B, Fogarty MJ, Sarmiento JL, Levin SA (2013) Marine taxa track local climate velocities. Science 341:1239-1242

Pratchett MS, Hoey AS, Wilson SK, Messmer V, Graham NA (2011) Changes in biodiversity and functioning of reef fish assemblages following coral bleaching and coral loss. Diversity 3:424-452
Quinn GP, Keough MJ (2002) Experimental design and data analysis for biologists. Cambridge University Press, Cambridge

Risk MJ (1972) Fish diversity on a coral reef in the Virgin Islands. Atoll Research Bulletin. doi:10.5479/si.00775630.153.1

Schiel DR, Steinbeck JR, Foster MS (2004) Ten years of induced ocean warming causes comprehensive changes in marine benthic communities. Ecology 85:1833-1839

Shulman MJ (1984) Resource limitation and recruitment patterns in a coral reef fish assemblage. J Exp Mar Bio Ecol 74:85-109

Shulman MJ (1985) Recruitment of coral reef fishes: effects of distribution of predators and shelter. Ecology 66:1056-1066

Soeparno, Nakamura Y, Yamaoka K (2013) Habitat choice and recruitment of tropical fishes on temperate coasts of Japan. Environ Biol Fishes 96:1-9

Tait LW, Schiel DR (2011) Legacy effects of canopy disturbance on ecosystem functioning in macroalgal assemblages. PLoS One 6:e26986

Thomas CD, Cameron A, Green RE, Bakkenes M, Beaumont LJ, Collingham YC, Erasmus BF, De Siqueira MF, Grainger A, Hannah L (2004) Extinction risk from climate change. Nature 427:145-148

Travis J (2003) Climate change and habitat destruction: a deadly anthropogenic cocktail. Proc $\mathrm{R}$ Soc Lond B Biol Sci 270:467-473

Underwood AJ (1997) Experiments in ecology: their logical design and interpretation using analysis of variance. Cambridge University Press, Cambridge

Urban MC, Zarnetske PL, Skelly DK (2013) Moving forward: dispersal and species interactions determine biotic responses to climate change. Ann N Y Acad Sci 1297:44-60

Velimirov B, Griffiths CL (1979) Wave-induced kelp movement and its importance for community structure. Botanica Marina 22:169-172

Vergés A, Steinberg PD, Hay ME, Poore AG, Campbell AH, Ballesteros E, Heck KL, Booth DJ, Coleman MA, Feary DA (2014) The tropicalization of temperate marine ecosystems: climate-mediated changes in herbivory and community phase shifts. Proc R Soc Lond B Biol Sci 281:20140846

Warren MS, Hill JK, Thomas JA, Asher J, Fox R, Huntley B, Roy DB, Telfer MG, Jeffcoate S, Harding P (2001) Rapid responses of British butterflies to opposing forces of climate and habitat change. Nature 414:65-69

Warwick RM (1986) A new method for detecting pollution effects on marine macrobenthic communities. Mar Biol 92:557-562

Wilson SK, Graham NA, Pratchett MS, Jones GP, Polunin NV (2006) Multiple disturbances and the global degradation of coral reefs: are reef fishes at risk or resilient? Glob Chang Biol 12:2220-2234

Wilson SK, Depczynski M, Fisher R, Holmes TH, O’Leary RA, Tinkler P, Unsworth RKF (2010) Habitat associations of juvenile fish at Ningaloo Reef, Western Australia: the importance of coral and algae. PLoS One 5:e15185

Wright KJ, Higgs DM, Belanger AJ, Leis JM (2005) Auditory and olfactory abilities of pre-settlement larvae and post-settlement juveniles of a coral reef damselfish (Pisces: pomacentridae). Mar Biol 147:1425-1434

Wu L, Cai W, Zhang L, Nakamura H, Timmermann A, Joyce T, McPhaden MJ, Alexander M, Qiu B, Visbeck M (2012) Enhanced warming over the global subtropical western boundary currents. Nat Clim Chang 2:161-166

Yamada H, Nanami A, Ohta I, Fukuoka K, Sato T, Kobayashi M, Hirai N, Chimura M, Akita Y, Kawabata Y (2012) Occurrence and distribution during the post-settlement stage of two Choerodon species in shallow waters around Ishigaki Island, southern Japan. Fish Sci 78:809-818 